\title{
Evaluating Behavioral Changes Prevalence Among Primary and Preschool Children Due to COVID-19 Epidemic
}

\author{
Ali Dashtgard (iD) ${ }^{1}$, Hossein Dehghani (iD) ${ }^{2}$, Seyed Mostafa Mohsenizadeh ${ }^{(i D}{ }^{1}$, Hadi Zare Marzouni (iD) \\ and Mohammad Alinezhad Moqaddam (iD) ${ }^{1, *}$ \\ ${ }^{1}$ Qaen School of Nursing and Midwifery, Birjand University of Medical Sciences, Birjand, Iran \\ ${ }^{2}$ School of Medicine Birjand University of Medical Sciences, Birjand, Iran \\ "Corresponding author: Qaen School of Nursing and Midwifery, Birjand University of Medical Sciences, Birjand, Iran. Email: mohammadalinegad23@yahoo.com
}

Received 2021 November 3; Accepted 2021 December 6.

\begin{abstract}
Background: The COVID-19 pandemic and its subsequent changes in the community lifestyle can be associated with problems and complications. It seems very important to identify the problems caused by the COVID-19 pandemic accurately.

objectives: This study aimed to investigate behavioral changes in children due to the COVID-19 pandemic in South Khorasan in 2021.

Methods: In this cross-sectional study, 312 children were studied. Inclusion criteria included all children under 12 years of age without apparent mental disorders and chronic diseases affecting behavioral changes. Exclusion criteria were parental separation, experiencing natural disasters in the last two years, losing a first-degree family member in the last two years, and any underlying disease in the child and first-degree family members. The questionnaires included a demographic questionnaire and the Ruther Children's Behavior Questionnaire, completed by parents online due to the COVID-19 epidemic and the new situation.

Results: The results showed that the behavioral disorder prevalence was $37.2 \%(n=116)$. The mean scores were $3.10 \pm 2.23$ for aggression-hyperactivity, $3.11 \pm 3.08$ for anxiety-depression, $2.65 \pm 1.79$ for social maladaptation, $2.34 \pm 1.83$ for antisocial behavior, and $1.59 \pm 1.29$ for attention deficit. There was no significant relationship between demographic indicators and behavioral disorders $(\mathrm{P}>0.05)$.
\end{abstract}

Conclusions: The results indicated an increase in the prevalence of behavioral disorders in children during the COVID-19 pandemic. Therefore, it seems necessary to identify influencing factors and find appropriate solutions to prevent such disorders.

Keywords: Behavioral Disorder, COVID-19, Children

\section{Background}

Coronaviruses belong to a large family of viruses that can cause zoonotic diseases. As a result of genetic modifications and pathogenicity extension, coronaviruses can be transmitted from an infected animal to humans, forming a new human coronavirus and causing a range of diseases from the common cold to more severe conditions such as the Middle East respiratory syndrome (MERS) and severe acute respiratory syndrome (SARS) (1-3). In December 2019, a novel human coronavirus outbreak was reported in Wuhan, China, which was a modified form of previous strains, thus named SARS-CoV-2 $(4,5)$. The SARS-CoV-2 virus is the family's newest member and is responsible for a new disease called coronavirus disease 2019 (COVID-19) (1-3, 5). The number of patients diagnosed with this disease is increasing day by day, and the disease's mortality rate has been regarded as $6.8 \%(4,5)$. Considering its high transmis- sion rate, COVID-19 poses a severe threat to global public health (6). Due to its novelty and limited therapeutic options, the best way to cope with this virus is to confine its $\operatorname{spread}(7,8)$.

Along with the risk of pathogenicity in the community, this disease can be associated with unbearable psychological pressure on people worldwide (5). Children are among the groups who are susceptible to psychological problems. In addition to suffering from clinical symptoms of the disease, they are also affected by psychological disorders resulting from social-behavioral changes. Ghosh et al. showed that children are more vulnerable and likely to suffer from psychological problems during crises, especially epidemics (9), due to their specific nutritional and behavioral patterns and their strong dependence on parents and caregivers (10). Children suffer a long-term fear of contracting the coronavirus and quarantine-associated 
unpleasant and boring thoughts and feel insecurity and physical and social isolation due to the lack of communication with classmates, friends, and teachers, the lack of proper space at home, and in some cases, parents' financial problems $(5,11,12)$.

Unfortunately, mental health and behavioral disorders have received low attention in Iran, as well as many countries across the world (13). Because the child is a vulnerable creature and incapable of self-protection, it is essential to implement behavioral disorder screening programs among children and manage these disorders to recognize the current situation and choose appropriate solutions (1, $5,14,15)$. Iran is a developing country, and almost half of its population is under 15 years old, so the health or disease of this population can significantly affect the health and disease of today and tomorrow communities (13). So far, no study has been conducted on behavioral disorders in children experiencing the social norms and constraints caused by the COVID-19 pandemic.

\section{Objectives}

The present study aimed to investigate behavioral changes caused by the COVID-19 pandemic among under 12-year-old Iranian children in 2021.

\section{Methods}

The present descriptive-analytical study was performed on children under 16 years in South Khorasan Province. Based on the indices obtained by the formula of estimating a ratio, the sample size was determined as 314 (13). All children under 16 years of age who had no history of mental disorders or chronic diseases affecting behavioral changes were included. Exclusion criteria were parental separation, experiencing natural disasters during the recent two years, losing a first-degree relative or a family member in the recent two years, and diagnosis of any underlying disease in the child and first-degree relatives.

The research tools included a demographic questionnaire and the Rutter Children's Behavioral Disorder Questionnaire (the parent version) (16). The test's total score for each individual ranged from zero to 62, and a score equal to or greater than 13 (the cutoff point) indicated that the child suffered from a behavioral disorder. Rutter reported the reliability of this questionnaire as 0.74 . This questionnaire has also been used in many studies in Iran to assess behavioral disorders among children, and its validity and reliability have been approved (17). The validity of the questionnaire was confirmed based on the content validity ap- proach, and its reliability was determined by the test-retest $\operatorname{method}(\mathrm{r}=0.82)$.

After obtaining the approval of the Ethics Committee of Birjand University of Medical Sciences (ethics code: IR.BUMS.REC.1399.044), an online questionnaire was designed. In the first part of the questionnaire, the study objectives were fully explained to parents, and guidance was provided on answering the questionnaire. Before entering the study, parents were asked to announce their consent for participation by checking a consent box on the form. Then, the demographic information checklist and the Rutter Children's Behavioral Disorder Questionnaire were provided to the parents online, and they were requested to complete and send the questionnaire based on their observations of the child's behavior during the COVID-19 pandemic.

Descriptive statistics, including frequency and standard deviation, and the chi-square test, ANOVA, and $t$-test were used to analyze the data. Statistical analyses were performed in SPSS 18 software.

\section{Results}

Out of 312 participants in this study, 179 (57.4\%) were girls, and 133 (42.6\%) were boys. The means of children's age and weight were $11.05 \pm 3.26$ years and $36.96 \pm 14.73 \mathrm{~kg}$, respectively. Also, the mean ages of mothers and fathers were $38.59 \pm 6.28$ and $43.35 \pm 7.79$ years, respectively. Most subjects were the first child in the family. The highest level of education among the parents was a high-school diploma. Regarding occupation, most mothers were housewives, and most fathers were self-employed. Financially, most families had an average level (Table 1).

The analysis of behavioral disorders' symptoms was done based on the questionnaire according to parents' perspectives, showing that the prevalence of behavioral disorders, based on all variables studied, was 37.2\% $(n=116)$. Also, the mean scores of aggression-hyperactivity symptoms, anxiety-depression, social maladaptation, antisocial behaviors, and attention deficit were $3.10 \pm 2.23,3.11 \pm 3.08$, $1.79 \pm 2.65,1.83 \pm 2.34$, and $1.59 \pm 1.29$, respectively. Regarding the relationship between demographic variables and behavioral disorders, none of the age, sex, occupation, parental education, number of children, and economic status variables was associated with behavioral disorders (P> 0.05).

Analyzing the relationship between the mean scores of behavioral disorder symptoms and demographic variables showed that age was significantly associated with social maladaptation and aggression-hyperactivity symptoms $(\mathrm{P}<0.05)$. In addition, maternal occupation was significantly associated with anxiety-depression symptoms 


\begin{tabular}{|c|c|}
\hline Variables & No. (\%) \\
\hline \multicolumn{2}{|l|}{ Age (y) } \\
\hline $2-6$ & $33(10.6)$ \\
\hline $7-11$ & $117(37.5)$ \\
\hline $12-16$ & $162(51.9)$ \\
\hline \multicolumn{2}{|l|}{ Gender } \\
\hline Boy & $133(42.6)$ \\
\hline Girl & $179(57.4)$ \\
\hline \multicolumn{2}{|l|}{ Number of children } \\
\hline 1 & $132(42.3)$ \\
\hline 2 & $102(32.7)$ \\
\hline 3 & $55(17.6)$ \\
\hline 4 & $23(7.4)$ \\
\hline \multicolumn{2}{|l|}{ Mother's education } \\
\hline Elementary school & $105(33.7)$ \\
\hline Diploma & $122(39.1)$ \\
\hline Bachelor's degree & $59(18.9)$ \\
\hline Master's degree & $26(8.3)$ \\
\hline \multicolumn{2}{|l|}{ Father's education } \\
\hline Elementary school & $94(30.1)$ \\
\hline Diploma & $121(38.8)$ \\
\hline Bachelor's degree & $63(20.2)$ \\
\hline Master's degree & $34(10.9)$ \\
\hline \multicolumn{2}{|l|}{ Father's job } \\
\hline Employee & $115(36.8)$ \\
\hline Self-employed & $156(50)$ \\
\hline Retired & $28(9)$ \\
\hline Unemployed & $13(4.2)$ \\
\hline \multicolumn{2}{|l|}{ Mother's job } \\
\hline Employee & $75(24)$ \\
\hline Self-employed & $12(3.8)$ \\
\hline Retired & $5(1.6)$ \\
\hline Housewife & $220(70.6)$ \\
\hline \multicolumn{2}{|l|}{ Economic status } \\
\hline Weak & $28(9)$ \\
\hline Moderate & $219(70.2)$ \\
\hline Good & $65(20.8)$ \\
\hline
\end{tabular}

$(P=0.04)$, and paternal education had a significant relationship with aggression-hyperactivity symptoms ( $\mathrm{P}=$ 0.009). Other demographic variables did not have a statistically significant relationship with behavioral disorders ( $P$ $>0.05$ ). Table 2 shows the relationship between the mean scores of behavioral disorder symptoms and demographic variables.

\section{Discussion}

The results showed that the prevalence of behavioral disorders in children during the COVID-19 pandemic was $37.2 \%$. Also, the mean scores of aggression-hyperactivity, anxiety-depression, social maladaptation, antisocial behavior, and attention deficit were higher than normal. These findings show that a high percentage of the participants developed behavioral disorders during the coronavirus pandemic. Our results also revealed no significant relationship between demographic variables and behavioral disorders. This observation can reflect that all children, independent of their demographic features, can present the signs of behavioral disorders during the pandemic.

Behavioral disorders in children are usually not recognized by parents until the child presents behavior beyond his/her age. Although behaviors such as disobedience, playfulness, or mischief are natural behaviors during childhood, if they become too severe and excessively annoying or happen repetitively, they are considered behavioral problems and must be corrected by appropriate treatments. There are various behavioral disorders in children, most commonly aggression, stubbornness, attention deficit, fear, robbery, hyperactivity, depression, autism, and various forms of phobias (18-20). It seems necessary to assess various reasons for the development of behavioral disorders.

In a study conducted by Deolmi and Pisani to investigate the effects of psychological factors on children and adolescents during the COVID-19 pandemic, the results revealed a high prevalence of anxiety and depressive symptoms among these individuals due to factors such as the disease outbreak, social isolation, and parents' stress. Also, the results indicated that students with higher education, girls, and children from low-income families were at a higher risk for developing psychiatric symptoms. In their study, Deolmi and Pisani highlighted an urgent need for planning and implementing new strategies and early psychological interventions to mitigate the impacts of the COVID-19 pandemic on the mental health status of children and adolescents (18). Therefore, it seems that with the outbreak of the COVID-19 disease, along with extensive efforts to improve therapeutic methods to cure patients, spe- 


\begin{tabular}{|c|c|c|c|c|c|}
\hline \multirow{2}{*}{ Variables } & \multicolumn{5}{|c|}{ Behavioral Disorder Symptoms } \\
\hline & Attention-Deficit & Antisocial Behaviors & Social Maladaptation & Anxiety-Depression & Aggression-Hyperactivity \\
\hline \multicolumn{6}{|l|}{ Age } \\
\hline $\mathrm{R}$ & -0.3 & -0.016 & 0.15 & -0.4 & 0.1 \\
\hline$P$ & $0.5^{\mathrm{a}}$ & $0.7^{\mathrm{a}}$ & $0.006^{\mathrm{a}}$ & $0.4^{\mathrm{a}}$ & $0.04^{\mathrm{a}}$ \\
\hline \multicolumn{6}{|l|}{ Gender } \\
\hline $\mathrm{T}$ & 0.01 & -0.2 & -0.9 & 0.02 & 0.8 \\
\hline $\mathrm{P}$ & $0.9^{\mathrm{b}}$ & $0.8^{\mathrm{b}}$ & $0.3^{\mathrm{b}}$ & $0.9^{b}$ & $0.1^{\mathrm{b}}$ \\
\hline \multicolumn{6}{|c|}{ Mother's job } \\
\hline df & 7 & 10 & 10 & 10 & 9 \\
\hline $\mathrm{P}$ & $0.6^{c}$ & $0.9^{c}$ & $0.9^{c}$ & $0.04^{\mathrm{c}}$ & $0.5^{c}$ \\
\hline \multicolumn{6}{|c|}{ Father's job } \\
\hline df & 7 & 10 & 10 & 10 & 9 \\
\hline $\mathrm{F}$ & 1.1 & 0.5 & 0.7 & 1.07 & 0.7 \\
\hline$P$ & $0.3^{c}$ & $0.8^{\mathrm{c}}$ & $0.6^{c}$ & $0.3^{c}$ & $0.6^{\mathrm{c}}$ \\
\hline \multicolumn{6}{|c|}{ Father's education } \\
\hline $\mathrm{df}$ & 7 & 10 & 10 & 10 & 9 \\
\hline $\mathrm{F}$ & 0.6 & 0.6 & 0.5 & 1.5 & 2.49 \\
\hline $\mathrm{P}$ & $0.7^{c}$ & $0.7^{\mathrm{c}}$ & $0.8^{\mathrm{c}}$ & $0.1^{\mathrm{c}}$ & $0.009^{c}$ \\
\hline \multicolumn{6}{|c|}{ Mother's education } \\
\hline $\mathrm{F}$ & 1.4 & 0.9 & 0.6 & 1.49 & 1.12 \\
\hline $\mathrm{P}$ & $0.1^{c}$ & $0.5^{c}$ & $0.7^{c}$ & $0.1^{c}$ & $0.3^{c}$ \\
\hline \multicolumn{6}{|c|}{ Number of children } \\
\hline df & 7 & 10 & 10 & 10 & 9 \\
\hline $\mathrm{F}$ & 1.1 & 1.3 & 1.31 & 1.5 & 1.2 \\
\hline $\mathrm{P}$ & $0.2^{c}$ & $0.2^{c}$ & $0.3^{c}$ & $0.1^{\mathrm{c}}$ & $0.2^{c}$ \\
\hline \multicolumn{6}{|c|}{ Economic status } \\
\hline df & 7 & 10 & 10 & 10 & 9 \\
\hline $\mathrm{F}$ & 1.1 & 0.9 & 0.7 & 0.3 & 1.7 \\
\hline $\mathrm{P}$ & $0.3^{c}$ & $0.5^{\mathrm{c}}$ & $0.6^{\mathrm{c}}$ & $0.9^{c}$ & $0.07^{c}$ \\
\hline
\end{tabular}

cial attention should be paid to the mental health of people in all social groups, especially those who are more vulnerable.

In a study by Wang et al. in 194 cities of China during the COVID-19 pandemic, 53.8\% of the respondents reported moderate to severe psychological impacts due to the COVID-19 outbreak. Also, 16.5\% of the subjects reported moderate to severe depression; $28.8 \%$ had moderate to se- vere anxiety symptoms, and 8.1\% reported moderate to severe stress levels. A recent study also showed that childhood, female gender, concomitant physical symptoms (muscle pain, dizziness, etc.), and a weak immune system were significantly associated with psychological disorders (19). Likewise, a cross-sectional study by Zhou et al. in China estimated the prevalence of depression and anxiety symptoms as $43.7 \%$ and $37.4 \%$, respectively, among 12-18-year- 
old Chinese students. In addition, 31.3\% of these students showed both disorder symptoms, and female students and those with higher education were at a higher risk for this condition. The results also showed adolescents' decreased interest in work, fatigue, anorexia/bulimia, irritability, restlessness, and easy temper (20). Consistent with the findings of the studies mentioned above, our results also indicated statistically significant relationships between the children's age and social maladaptation and aggression/hyperactivity symptoms, between maternal job and anxiety-depressive symptoms, and finally between paternal education and aggression/hyperactivity symptoms. Therefore, it seems that demographic parameters such as age, gender, education, and the relationship between family members can be essential determinants affecting people's psychological and behavioral well-being and their responses to unfortunate events.

In a study, Jiao et al. investigated behavioral and emotional disorders in children during the COVID-19 pandemic and reported a high prevalence of fear, uncertainty, and physical and social isolation among the subjects studied (14). Also, Liu et al. assessed the relationship between home quarantine and children's stress and showed severe symptoms such as fear and sorrow following the quarantine (21). In another study during the coronavirus outbreak, Zhang et al. showed a rise in the prevalence of mood disorders, acute stress, and behavioral problems among children due to the closure of medical centers and staying at home regulations (22). Besides, Ghosh et al. delineated problems such as abuse, negligence, sleep disorders, and education problems in children during the COVID-19 outbreak (9), which agreed with our results regarding the presence of behavioral problems and disorders among children. Moreover, studies suggest that in addition to children, adults can also develop behavioral disorders during the COVID-19 pandemic. It can be concluded that social isolation, quarantine regulations, and confined social communications can contribute to the development of behavioral and psychological disorders among children during the COVID19 pandemic, leading to depression, anxiety, or physical symptoms. Some studies also suggest that social isolation and psychological disorders can culminate in psychotic attacks and suicidal thoughts, which are more prevalent among youths. In addition, addictive disorders may be raised following these problems. Furthermore, a history of underlying diseases may exaggerate the fear of death, anxiety, and depression in people who are quarantined (18). Therefore, it is essential to maximize efforts to resolve these detrimental factors during the pandemic.

Evidence suggests that during the COVID-19 pandemic, the feelings of fear, anger, and sorrow, as well as anxietyrelated insomnia, are more common in quarantined chil- dren and adolescents than in their non-quarantined peers (23-25). Studies show that the COVID-19 pandemic has caused many changes in children and adolescents' daily lives; on the other hand, stressful events at an early age can lead to psychological collapse (26). In a study conducted by Ozamiz-Etxebarria et al. to assess stress, anxiety, and depression levels in the early stages of the COVID19 outbreak in Spain, the findings showed significant increments in anxiety, stress, and depression compared to before the onset of the pandemic. Also, younger people with chronic diseases reported more symptoms than others. A recent study declared a rise in these symptoms after the announcement of global quarantine regulations. Altogether, researchers have suggested implementing psychological interventions to prevent and treat these conditions to alleviate the psychological impacts of the pandemic (27). These findings are consistent with those of our study. In this regard, we showed an increase in the mean score of anxiety and depression in the studied population during the coronavirus period, indicating the considerably adverse psychological effects of the COVID-19 pandemic on children.

In particular, the risk of some psychological disorders increases during adolescence (ie, when mental health is developing). Amid the coronavirus pandemic, social distancing can exaggerate mental imbalance and exacerbate psychiatric disorders in individuals with underlying mental illnesses. Disruption of daily activities and losing contact with peers may lead to insecurity in children. In addition, the closure of schools mainly affects children with special needs, who cannot expand their essential skills, so their families are compelled to take care of them at home without the help of instructors (28). The critical point is that even after quarantine, its long-term impacts can affect children's mental well-being and lead to a posttraumatic stress disorder, so that they may experience difficulties in resuming their social activities and establishing interactions with others. Nevertheless, with the closure of schools, social service providers, and healthcare centers, it is challenging to diagnose mental health problems in children and adolescents and reach appropriate psychological and psychiatric therapeutic interventions. These children must receive early psychological interventions in all cases, so it is necessary to seek more resources and implement new strategies to provide emotional support to them (29).

According to this study and other similar reports, it is possible to reduce the risk of mental disorders in children and adolescents by maintaining their communication with their peers through social media and regularly updating the government's instructions through mass media. Also, online resources on mental health education and preventive measures of psychological disorders, 
video-based counseling, and telemedicine psychiatry services can help reduce the psychosocial effects of the coronavirus pandemic.

\subsection{Conclusions}

The results of this study indicated an increase in the prevalence of behavioral disorders in children during the COVID-19 pandemic, highlighting the need for paying particular attention to these problems during the pandemic, especially in vulnerable groups such as children. Therefore, it is vital for health system authorities to focus on this issue and make strategic decisions to address this problem. Moreover, one cannot ignore the vital role of parents in reducing the incidence of these disorders.

\section{Acknowledgments}

This study was carried out with the support of the ViceChancellor for Research of Birjand University of Medical Sciences, Birjand, Iran. Also, the researchers would like to thank all the participants in the study.

\section{Footnotes}

Authors' Contribution: Ali Dashtgard: Study concept and design and acquisition of data; Hossein Dehghani: Sampling and article writing; Seyed Mostafa Mohsenizadeh: Analysis and interpretation of data and statistical analysis; Hadi Zare Marzouni: Article writing and critical revision of the manuscript for important intellectual content; Mohammad Alinejad Moghaddam: Administrative, technical, material support, and study supervision.

Conflict of Interests: There is no conflict of interest in this study.

Data Reproducibility: The data presented in this study are openly available in one of the repositories or will be available on request from the corresponding author by this journal representative at any time during submission or after publication. Otherwise, all consequences of possible withdrawal or future retraction will be with the corresponding author.

Ethical Approval: This study was approved by the Ethics Committee of Birjand University of Medical Sciences, Birjand, Iran, by Ethical code: IR.BUMS.REC.1399.044.

Funding/Support: The study was financially supported by Birjand University of Medical Sciences in Iran.

Informed Consent: Informed consent was obtained from the participants online at the beginning of each questionnaire completion.

\section{References}

1. Guan WJ, Ni ZY, Hu Y, Liang WH, Ou CQ, He JX, et al. Clinical Characteristics of Coronavirus Disease 2019 in China. NEngl JMed.2020;382(18) doi: 10.1056/NEJMoa2002032. [PubMed: 32109013]. [PubMed Central: PMC7092819].

2. Huang C, Wang Y, Li X, Ren L, Zhao J, Hu Y, et al. Clinical features of patients infected with 2019 novel coronavirus in Wuhan, China. Lancet 2020;395(10223):497-506. doi:10.1016/s0140-6736(20)30183-5.

3. Lu R, Zhao X, Li J, Niu P, Yang B, Wu H, et al. Genomic characterisation and epidemiology of 2019 novel coronavirus: implications for virus origins and receptor binding. Lancet. 2020;395(10224):565-74. doi:10.1016/s0140-6736(20)30251-8.

4. Zhu H, Wei L, Niu P. The novel coronavirus outbreak in Wuhan, China. Glob Health Res Policy. 2020;5:1-3. doi: 10.1186/s41256-020-001356. [PubMed: 32226823]. [PubMed Central: PMC7050114].

5. Mohammadi MT. Psychological Impacts of Covid-19 Outbreak on Mental Health Status of Society Individuals: A Narrative Review. J Mil Med. 2020;22(2):184-92.

6. Zare Marzouni H, Dashtgard A, Hamounpeyma E. Ascending and Descending of Coronavirus Disease 2019 (COVID-19). Galen Med J. 2020;9. e1880. doi: 10.31661/gmj.v9i0.1880. [PubMed: 34466604]. [PubMed Central: PMC8343768].

7. Liang Y, Chen M, Zheng X, Liu J. Screening for Chinese medical staff mental health by SDS and SAS during the outbreak of COVID-19. J Psychosom Res. 2020;133:110102. doi: 10.1016/j.jpsychores.2020.110102. [PubMed: 32224344]. [PubMed Central: PMC7139244].

8. Chaturvedi SK. Covid-19, Coronavirus and Mental Health Rehabilitation at Times of Crisis. J Psychosoc Rehabil Ment Health. 2020:1-2. doi: 10.1007/s40737-020-00162-z. [PubMed: 32292688]. [PubMed Central: PMC7114947]

9. Ghosh R, Dubey MI, Chatterjee S, Dubey S. Impact of COVID -19 on children: special focus on the psychosocial aspect. Minerva Pediatr. 2020;72(3). doi: 10.23736/S0026-4946.20.05887-9. [PubMed: 32613821].

10. Ghanizade Bafghi M. The Effects of COVID19 on Child's Rights and the Protective Strategies; by Emphasizing on the Convention on the Rights of the Child. J Law Res. 2020;23(91).

11. Brooks SK, Webster RK, Smith LE, Woodland L, Wessely S, Greenberg $\mathrm{N}$, et al. The Psychological Impact of Quarantine and How to Reduce It: Rapid Review of the Evidence. SSRN Electronic J. 2020. doi: 10.2139/ssrn.3532534.

12. Zandifar A, Badrfam R. Iranian mental health during the COVID-19 epidemic. Asian JPsychiatr.2020;51:101990. doi:10.1016/j.ajp.2020.101990. [PubMed: 32163908]. [PubMed Central: PMC7128485].

13. Khodam H, Modanlou MM, Ziaei T, Keshtkar AA. Behavioral disorders and related factors in school age children of Gorgan. Iran J Nurs Res. 2009.

14. Jiao WY, Wang LN, Liu J, Fang SF, Jiao FY, Pettoello-Mantovani M, et al Behavioral and Emotional Disorders in Children during the COVID 19 Epidemic. J Pediatr. 2020;221. doi: 10.1016/j.jpeds.2020.03.013. [PubMed: 32248989]. [PubMed Central: PMC7127630].

15. Nicholas DB, Gearing RE, Koller D, Salter R, Selkirk EK. Pediatric epidemic crisis: Lessons for policy and practice development. Health Policy. 2008;88(2-3):200-8. doi:10.1016/j.healthpol.2007.11.006. [PubMed: 18456367]. [PubMed Central: PMC7132509].

16. Rutter M. A children's behaviour questionnaire for completion by teachers: preliminary findings. J Child Psychol Psychiatry. 1967;8(1):1-11

17. Jalilian F, Rakhshani F, Ahmadpanah M, Zinat Motlagh F, Moieni B, Moghimbeigi A, et al. Prevalence of behavioral disorders and its associated factors in Hamadan primary school students. Avicenna J Clin Med. 2013;19(4):62-8.

18. Deolmi M, Pisani F. Psychological and psychiatric impact of COVID-19 pandemic among children and adolescents. Acta Biomed. 2020;91(4). 
19. Wang C, Pan R, Wan X, Tan Y, Xu L, Ho CS, et al. Immediate Psychological Responses and Associated Factors during the Initial Stage of the 2019 Coronavirus Disease (COVID-19) Epidemic among the General Population in China. Int J Environ Res Public Health. 2020;17(5). doi: 10.3390/ijerph17051729. [PubMed: 32155789]. [PubMed Central: PMC7084952].

20. Zhou SJ, Zhang LG, Wang LL, Guo ZC, Wang JQ, Chen JC, et al. Prevalence and socio-demographic correlates of psychological health problems in Chinese adolescents during the outbreak of COVID-19. Eur Child Adolesc Psychiatry. 2020;29(6):749-58. doi: 10.1007/s00787020-01541-4. [PubMed: 32363492]. [PubMed Central: PMC7196181].

21. Liu JJ, Bao Y, Huang X, Shi J, Lu L. Mental health considerations for children quarantined because of COVID-19. Lancet Child Adolesc Health. 2020;4(5):347-9. doi: 10.1016/s2352-4642(20)30096-1.

22. Zhang J, Shuai L, Yu H, Wang Z, Qiu M, Lu L, et al. Acute stress, behavioural symptoms and mood states among school-age children with attention-deficit/hyperactive disorder during the COVID-19 outbreak. Asian J Psychiatr. 2020;51:102077. doi: 10.1016/j.ajp.2020.102077. [PubMed: 32315967]. [PubMed Central: PMC7195413].

23. Saurabh K, Ranjan S. Compliance and Psychological Impact of Quarantine in Children and Adolescents due to Covid-19 Pandemic. Indian J Pediatr. 2020;87(7):532-6. doi: 10.1007/s12098-020-03347-3. [PubMed: 32472347]. [PubMed Central: PMC7257353].

24. Liu X, Luo WT, Li Y, Li CN, Hong ZS, Chen HL, et al. Psychological status and behavior changes of the public during the COVID-19 epidemic in China. Infect Dis Poverty. 2020;9(1):1-11. doi: 10.1186/s40249-020-006783. [PubMed: 32471513]. [PubMed Central: PMC7256340].

25. Sharma V, Reina Ortiz M, Sharma N. Risk and Protective Factors for Adolescent and Young Adult Mental Health Within the Context of COVID-19: A Perspective From Nepal. J Adolesc Health. 2020;67(1):135. doi: 10.1016/j.jadohealth.2020.04.006. [PubMed: 32444197]. [PubMed Central: PMC7237905].

26. Sani G, Janiri D, Di Nicola M, Janiri L, Ferretti S, Chieffo D. Mental health during and after the COVID-19 emergency in Italy. Psychiatry Clin Neurosci. 2020;74(6):372. doi: 10.1111/pcn.13004. [PubMed: 32248608].

27. Ozamiz-Etxebarria N, Dosil-Santamaria M, Picaza-Gorrochategui M, Idoiaga-Mondragon N. Stress, anxiety, and depression levels in the initial stage of the COVID-19 outbreak in a population sample in the northern Spain. Cad Saude Publica. 2020;36(4). e00054020. doi: 10.1590/0102-311X00054020. [PubMed: 32374806].

28. Lee J. Mental health effects of school closures during COVID-19. Lancet Child Adolesc Health. 2020;4(6). doi: 10.1016/s2352-4642(20)30109-7.

29. Golberstein E, Wen H, Miller BF. Coronavirus Disease 2019 (COVID19) and Mental Health for Children and Adolescents. JAMA Pediatr. 2020;174(9):819-20. doi: 10.1001/jamapediatrics.2020.1456. [PubMed: 32286618]. 